\title{
Transnational literacies as social remittances: the role of language ideologies in shaping migrants' online literacies
}

Article

Accepted Version

Capstick, T. (2020) Transnational literacies as social remittances: the role of language ideologies in shaping migrants' online literacies. Applied Linguistics, 41 (2). pp. 301319. ISSN 1477-450X doi:

https://doi.org/10.1093/applin/amz009 Available at https://centaur.reading.ac.uk/79704/

It is advisable to refer to the publisher's version if you intend to cite from the work. See Guidance on citing.

To link to this article DOI: http://dx.doi.org/10.1093/applin/amz009

Publisher: Oxford Journals

All outputs in CentAUR are protected by Intellectual Property Rights law, including copyright law. Copyright and IPR is retained by the creators or other copyright holders. Terms and conditions for use of this material are defined in the End User Agreement. 


\section{CentAUR}

Central Archive at the University of Reading

Reading's research outputs online 


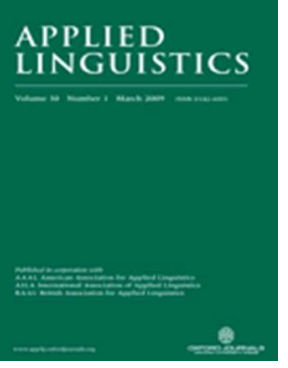

Transnational literacies as social remittances: the role of language ideologies in shaping migrants' online literacies

\begin{tabular}{|r|l|}
\hline Journal: & Applied Linguistics \\
\hline Manuscript ID & APPLING-17-11-357.R1 \\
\hline Manuscript Type: & Article \\
\hline Keyword: & transnational literacies, social remittances, language ideologies \\
\hline \multicolumn{2}{|l}{} \\
\hline
\end{tabular}

\section{SCHOLARONE}

Manuscripts 


\title{
Transnational literacies as social remittances: the role of language ideologies in shaping migrants' online literacies
}

\begin{abstract}
It is now twenty years since the term 'social remittances' was taken up to capture the notion that migration involves the circulation of ideas, practices, identities and social capital between destination and origin countries, in addition to the more tangible circulation of money. In a similar vein, a social theory of literacy sees practices not as observable units of behaviour but rather as social processes which connect people. To identify how literacy practices can be seen as social remittances, I identify how Usman, the key respondent in this study, goes about describing his first six months in the UK by tracing the meaning-making trajectories in our interviews together. I then explore the language and literacy choices that his family and friends make on Facebook as they remit ideas, beliefs and practices in their transnational literacies. I examine how these practices are shaped by beliefs about language. The paper seeks to understand the relationship between migrants' literacy practices before and after their migrations and how these practices remit ideas and beliefs which maintain transnational migration.
\end{abstract}

\section{Short title: transnational literacies as social remittances}

Word count: 8,493

\section{Introduction}

At the time this study was being carried out, Pakistan was firmly in the international news due to the US-led war in the Afghan-Pakistan borders. However, it is poverty as well as conflict which limits access to literacy in the national language, Urdu, and the official 
language, English in Pakistan (Ayres 2009). These constraints increase the desire for many Pakistanis to migrate to the UK given the strong transnational migration which has developed since the UK requested Pakistani migrants fill the labour shortages in its textile mills, over 70 years ago. This study focuses on Mirpur, a division of Pakistan-administered Kashmir, known as 'Little England', and Lancashire, in the north west of England, an area in which consecutive UK governments have sought to connect a lack of English language skills with social segregation (Blackledge 2005). Much has been written about the impact of economic remittances on Mirpur from the UK (Ballard 1991; 2003). However, this study focuses attention on the non-economic remittances which circulate across transnational networks in the form of literacies. These remittances are the circulatory exchanges which migrants send and receive in the form of written and spoken correspondence and include the ideas and practices from which they draw in these exchanges (Levitt 2016: 225). Conceptualising literacy in this way develops current research which accounts for literacy as a shared resource for multilingual communities (Blommaert 2008; Author 2016a) and extends this research to include literacy resources in countries of origin as well as countries of settlement.

Empirical data from Pakistan and the UK are examined to identify the ideological traces which shape literacy practices in both countries. Hanks suggests that the lens of practices helps re-think the relation between language and context by integrating the two "while overcoming the debilitating dichotomy between local and large-scale contexts' (2005: 191). Kell has sought to bridge this dichotomy by tracing how meaning-making shifts across space and time (2008). When working with large amounts of ethnographic data, Kell found that events would often link to other events but participants in these events did not always map one to one: 'literacy practices were not an in end in themselves analytically, but distributed across broader sequences of events' (2008: 259). Similarly, recent work in social remittances recognises the interconnectedness of the economic, social and cultural aspects of migration 
and seeks to demonstrate how economic remittances are part of a wider set of transnational practices which cannot be understood separately (Lacroix, Levitt and Vari-Lavoisier 2016). In the $\mathrm{PhD}$ study on which the present study is based, I found that this interconnectedness revealed the constraints of single-instance analysis and wish to extend this analysis in the present study by analysing new data with a new theoretical framework. As with Kell's work, meaning-making shifted from moment to moment and across spaces in Pakistan and the UK as I examined one family's transnational literacies. In the present paper, I move beyond the single instance in an attempt to understand how remitted literacies are shaped ideologically by the beliefs migrants hold about language while simultaneously accounting for the movements individuals were making across space and time when using those literacies.

Formal literacy in Mirpur is in Urdu since the British substituted it for Persian in the 1840's. However, Mirpuri Punjabi (along with Potwari) is the language most widely spoken in homes in Mirpur (Lothers and Lothers 2007), though it is not a language that was written down to any great extent until social media began to provide the affordances for the creation of romanized scripts for Punjabi. These scripts are taken up alongside non-standard varieties for Urdu and English as online interactants choose which varieties they use and how they wish to use them. This use is always shaped by the socio-historical and political processes of which these practices are part (Warriner 2007). English has played an increasingly central role in Mirpur for prospective migrants wishing to join their spouses in the UK since November 10 2010, five months after the start of the fieldwork for the $\mathrm{PhD}$ study, as the British government introduced English language testing for spousal migrants. The present study focuses on one of these migrants, Usman, and his transnational relationships with friends and family around the world in order to understand what a transnational optic reveals about migration, social inclusion and unbounded understandings of the nation state (Levitt 2016; Vertovec 2007). These understandings are also a central feature of Warriner's work on transnational literacies 
(2007) in which she connects everyday literacy practices to multi-stranded social relations across two or more nation-states. For Warriner, literacy practices maintain as well as transform these social relations just as they transform identities. Similarly, in Levitt's early work, migrants' notions of identity also shifted as a result of changes in their social status brought about by migration (1998: 934). For Levitt, in adjusting to their new lives, migrants bring a set of social and cultural tools in the form of social remittances:

They make sense of their experiences using the interpretive frames they bring with them. Just as institutional actors' choices are curtailed and facilitated by routines and norms already in place, so the new behaviours and views that migrants adopt are also a function of how things were done at home. A number of 'blending scenarios' result. In some cases, existing ideas and practices go unchallenged. In still others, creolization occurs, where new social relations and cultural patterns are created. (Levitt, 1998: 93).

In this paper, I take these 'interpretative frames' to include the language ideologies which shape migrants' language practices. In this sense I orient to an understanding of multilingualism which signals the multiplicity of communicative purposes which are associated with written and spoken languages alongside the traces of the language ideologies and social structures of origin countries (Martin Jones and Jones 2000). I take language ideologies to mean sets of beliefs and feelings about language which, when explored, expose relations between these beliefs about language and the language user's social world. These language ideologies are less about language alone but more socially situated and embedded in questions of identity and power in societies (Woolard 1998; Irvine and Gal 2000).

Questions of identity and power are currently at the forefront of UK-wide debates about notions of belonging in Britain. At the time this research was carried out, the Pakistani 
community, among other Muslim minority language groups, was facing increased pressure to demonstrate their allegiance to 'British values' through a growing conflation of English language proficiency with community cohesion (Blackledge 2005). Blackledge's analysis reveals complex chains of discourse in political actors' linking of violence on the streets of Lancashire in 2001 to some Asian residents' inability to speak English whereas contemporary research in critical sociolinguistics demonstrates how minority languages do not prevent migrants from belonging in their new homes if they do not learn English (Wodak 2011; Author 2018). This paper seeks to integrate work on transnational literacies with this work on minority language use by investigating the mobility of people, languages, texts and practices in the contexts of migration. I do this by considering how theoretical concepts from migration studies can be brought together with concepts from sociolinguistics to understand how language ideologies shape transnational literacies by asking similar questions to Warriner: 'what literacy practices do transmigrants develop while adapting to new contexts and what resources are used in doing so? (2007: 267). I extend this question by focusing in particular on the language resources that migrants draw on in their literacies and, specifically, how these language resources are ideologically shaped in the country of origin prior to departure. Ballard has written extensively about the replication of cultural norms which occurred in Mirpuri communities in Lancashire as migrants tended to live in 'ethnic colonies' in close proximity to each other (2008: 41). Ballard explains how these migrants were able to offer support to each other through 'networks of mutual reciprocity' (2008: 45). This reciprocity, I will argue, can be seen today in the literacies which help sustain migration between the two countries. They are, I suggest, based on what Ballard calls 'ideologies of kinship' (2008: 50), the belief that it is a duty to help family members and friends benefit from migration, which has resulted in the contemporary phase of this chain known as marriage migration (Charsley 
2005). It is as a result of these networks of mutual reciprocity that Usman in Mirpur was invited to marry Nadia in Lancashire in 2009.

\section{Theoretical Framework}

Levitt has outlined four types of social remittances: norms, practices, identities and social capital (1998: 2001). The theoretical framework for this study brings these four types of remittance together with a social practices theory of literacy (Baynham and Prinsloo 2009; Barton and Hamilton 1998; Street 1984). These practices involve values, attitudes and social relationships and are therefore close in meaning to the norms which, for Levitt, consist of ideas, values and beliefs which, she suggests, include notions of intrafamily responsibility, aspirations of social mobility and standards of age and gender appropriateness (1998: 933). Each of these will be explored in the data analysis of this paper. Levitt explains that these norms are shaped by practices which include religious practices, household labour and patterns of civil and political participation (1998; 2001). Thus, conceptualising literacy practices as social remittances means bringing together the two types of social remittances which Levitt describes as norms and practices.

Levitt's third type of social remittance is identity. She argues that notions of identity shift with the changes which migration brings about. She illustrates this with the example of the Miraflores migrant women from Dominican Republic who modified their ideas about women's roles in response to their more active engagement in the workplace in Boston US which in turn impacted non-migrant women who used these social remittances to construct new versions of womanhood (1998: 934). Thus, identities change over time and are given shape by the values people hold. Similarly, Ivanič et al. have argued that literacy practices involve a complex negotiation of identities which are held together by values (2009: 50). For example, how migrants choose different literacies to stay in touch with family and friends 
will relate to their values formed before and after migration. Their purpose for staying in touch could be financial, related to kinship, or out of a desire to remain friends, but in all cases their identities affect which literacy practices they maintain, take up or relinquish. This is because the meaning and value which individuals attach to literacy practices are shaped by their identities, which are in turn shaped by the values that they hold.

Finally, in her work in Miraflores/Boston, Levitt found that both the values and norms on which social capital is based were also socially remitted. Levitt draws on Portes and Sensenbrenner (1993: 1323) here when they define social capital as 'those expectations for action within a collectivity that affect the economic goals and goal-seeking behaviour of its members, even if these expectations are not oriented toward the economic sphere' (cited in Levitt 1998: 935). The notion that literacy in dominant languages such as English brings success in formal education and increased employment opportunities has emerged as a powerful determinant of development initiatives around the world and establishes a strong, if disputed link, between an autonomous model of literacy and its role in increasing social capital (Street 1994). As discussed earlier, in the Pakistan context, literacy in both Standard Urdu and Standard English are highly valued in economic terms in Pakistan but there are other varieties of both languages which have emerged since independence from Britain which, I will demonstrate later, carry social capital for Mirpuri migrants.

Having looked at how the foundational concepts from a social remittances approach to analysing migrants' exchanges can be brought together within a social theory of literacy I now turn to more recent work on social remittances to explain my contribution in this paper. In 2010, Levitt and Lamba-Nieves clarified the concept of social remittances in three ways by: stressing their circular nature, showing how they can be scaled out to other domains of practice and by including collective remittances. The theoretical thread which brings these three points together within a literacy practices approach can be explained through work on 
language ideologies. Language ideologies refer to sets of beliefs and feelings about language which, when explored, expose relations between these beliefs about language and the language user's social world. To understand how migrants' literacies circulate as social remittances we can identify how the norms, practices, identities and social capital that are remitted in transnational literacies are influenced by family members' ideas about specific languages. This is because language ideologies play out through everyday literacies associated with different domains of life and because these domains include school, home, workplaces and the spaces in-between. A conceptualisation of literacy exchanges as social remittances can reveal their circulatory nature by explaining what happens when these exchanges are scaled out to other domains of practice. Because 'there are questions of the permeability of boundaries, of leakages and movement between boundaries, and of overlap between domains (Barton and Hamilton 2000: 11) by tracing what happens when these literacy exchanges permeate boundaries it is possible to tease out how migrants' practices are created and appropriated across time and space. Doing so helps shed light on how private context 'appears to be infiltrated by practices from many different public domains' (ibid). It is in this convergence of public and private literacy practices that I trace the circular nature of social remittances as they are given their meaning by migrants' beliefs about language and wider society.

\section{Methodological approach}

This study is based on a multi-sited ethnography which accounted for migrants' literacies when they moved across national borders and the boundaries between domains, creating new spaces as well as new relationships along these trajectories. In doing so, the methods assembled here question traditional dichotomies between local and global, centre and periphery and micro and macro juxtapositions (Warriner 2007). In this sense, the 
framework is similar to Kell's recent work which combines meaning-making over space and time on the emic plane by focusing on the variable resources which come into play and configure the distribution of meaning (2015: 424). Whereas Kell's trans-contextual analysis identifies the variable resources at play in configuring distribution, my approach attends to the ideological shaping of these resources as individuals re-configure them moment to moment to suit their immediate communicative purposes online. I extend the broader PhD study from which this work originated by analysing ethnographic fieldnotes and interviews which had not been analysed previously. Thus, I rely on both ethnographic accounts of specific events as well as sociological analysis of wider social, economic and institutional contexts. Researching migration from Pakistan to the UK at the micro level required a historical perspective, encompassing events prior to the Partition of India in 1947 to the present day. I combined this with a trans-contextual methodology as I lived in both Pakistan and Lancashire when carrying out the ethnography.

As with Kell's work, the trajectories of migrants in my own study could not be understood with single-instance analysis, as participants' meaning-making shifted across time and space. These were physical spaces in Pakistan and the UK as well as social spaces such as Facebook and Instant Messaging. In this paper, I draw on data sets (interview data with Usman from April 2012) and re-analyse previous data sets (interview data from the broader $\mathrm{PhD}$ study). I also introduce the work on social remittances into the analysis and draw on Kell's more recent work looking at resources for projecting meaning-making (2015) to capture the circular nature of the social remittances across the different data sets.

The data analysed in the following section of this paper include interview data collected before Usman's departure from Pakistan though the majority of interview data were collected during a six-month period from January to April 2012 after his arrival in the UK. This was a period when Usman was experiencing the shock of leaving behind family and friends and 
settling into a new environment. Following Kell, I broke down the ethnographic data collected during this period into a series of strips of approximate timescales (2015:429) to capture the complexity of movement in time and space as he constructs and maintains multiple belongings. I did this so that I could link what Usman was telling me in interviews about his literacy practices to what he was telling me in the interviews about his 'new' life and how the two were linked. Kell explains that each meaning-making trajectory should be seen as small threads in relation to wider sets of trajectories operating on different scales. By organising the data into trajectories, I was able to plot Usman's movement through physical and social spaces immediately after his migration before introducing the analysis of his beliefs about his language and literacy practices. In other words, I link the meaning-making trajectories outlined in this methodology section, which bring together different dimensions of his personal history, experience and environment, to the analysis of language ideologies which shape his literacy practices during this time-period. I identified the following meaningmaking trajectories (MMT) across the six months:

MMT1. Usman arrives in Lancashire and spends time with his new family (three weeks).

MMT2: Usman spends time meeting extended family members but is mainly at home without work (seven weeks)

MM3: Usman starts work at both a taxi company and a take away restaurant (one month)

MM4: Usman establishes himself at work (one month)

As can be seen from the trajectories above, literacy practices were not an end in themselves analytically but were distributed across broader sequences of events. Organising the data into strips enabled a systematic framework for connecting the locations and timings of Usman's Facebook postings with the meaning-making trajectories of his arrival and experiences of 


\begin{tabular}{|l|l|l|l|l|}
\hline Month & $\begin{array}{l}\text { Meaning-making } \\
\text { trajectory }\end{array}$ & Online & Interview & Fieldnotes \\
\hline January & MM1-MM2 & & & $\begin{array}{l}\text { Visit Usman } \\
\text { at home }\end{array}$ \\
\hline February & MM2-MM3 & Trafford & & Visit take \\
& & & Trafford self- & Visit taxi \\
March & MM3 & & report interview & office \\
\hline April & MM3-MM4 & Ethnographic & Visit Usman \\
& & Poor Noor & & at home \\
\hline May & MM4 & 'What's going & Poor Noor self- & Visit Usman \\
& & on' 'Nofing' & report interview & at home \\
\hline June & MM4 & & & Visit Usman \\
& & & &
\end{tabular}

\section{Meaning-making trajectory 3}

Strip 1: Starting work in the taxi office

Strip 2: Starting work in the take away restaurant

Strip 3: Getting to know the taxi drivers at the base (speaking 'Pahari') 
Strip 4: The fight with a co-worker (swearing in 'Pahari')

Strip 5: Getting to know the co-worker from Gujaranwala (speaking Urdu)

Usman had started work in the take away and taxi office and was developing relationships with his colleagues. There were five strips in this trajectory. One of the strips revealed that Usman was working through the night. He worked from $3 \mathrm{pm}$ to $1 \mathrm{am}$ at the take away then went straight to the taxi firm where he worked on the radio/talking to customers from 1am to 6am. He would then go home, sleep and repeat the shifts. Another strip revealed that Usman had had a physical fight with a 'British-born' co-worker who 'went beserk' when Usman had responded to his mocking him for being new to the country.

Organising the data into strips brings together these disparate parts of different interviews and fieldnotes into a timescale that reveals, for example, that when Usman is posting online from the taxi office he is also using spoken Pahari with the men in the taxi office. The strips also enabled me to analyse my fieldnotes alongside the interview data and establish how lonely Usman was feeling when I visited him at home as he hadn't made any friends outside the immediate family. With the data spatially and temporally organised in this way I then returned to the interview data where Usman and I discuss his Facebook postings, re-analysed how he justified his language practices and how this shapes the literacies he remits.

\section{Literacy in Mirpur}

Social remittances can be separated from other forms of cultural circulation by nature of the fact that they are practices which are adapted and appropriated by individuals and families as the result of interpersonal communication (Levitt 2016: 225). Before identifying how Usman's literacy practices are taken up after his migration it is necessary to identify those individuals and institutions which sponsor, that is promote or prevent literacy (Brandt 
1998), in the domains of home and school prior to his migration. If we are to see understand the circulatory nature of Usman's remittances then it is first necessary to identify where they originated and how they were given their initial value.

Usman attended both English-medium and Urdu-medium schools as his father was in the army and the family moved from garrison to garrison. Each school sponsored a different type of literacy: Usman recalled that the army schools promoted literacy in Urdu but many of the teachers spoke in English, whereas the English medium schools sponsored literacy in Urdu and English while using spoken Urdu with code-switching to English in the classroom. Rassool (2007: 245) suggests that the choice of particular languages for teaching and learning, in this case English and Urdu, takes on an ideological function in defining the ethno-cultural basis of the politically constructed nation. For Rassool, language-in-education policy legitimates forms of knowledge which in turn are legitimated as hegemonic cultural capital. This cultural capital is imbued in Usman's aspirations to learn English for himself while sharing his literacy skills in English with his two brothers which he did regularly at home. Rassool goes on to argue that this ideological function plays a further role in 'imbuing learners with sets of beliefs, mores, traditions, and values embedded in the dominant culture, and through this serves to shape the cultural norms of society as a whole' (ibid) thereby linking school language policy to the literacies migrants will remit in later life.

On failing to realise his long-held goal of joining the military, Usman's aspirations to use English were unexpectedly called on when a British-Mirpuri family approached Usman's father with a suggestion of marriage to their daughter Nadia who had seen Usman in a video (which Levitt identifies as a key social remittance) of a Mirpuri wedding. Within a matter of months Nadia had flown out to Mirpur from the UK for five weeks, met Usman, married him, and fallen pregnant with their first son (her third child as Nadia is divorced). Nadia made it 
clear to me in interviews that she wanted a Mirpuri husband for her second marriage after her first marriage to a 'British-Mirpuri'. Usman joined Nadia in Britain in November 2011 after his second visa application was successful. The language and literacy learning experiences of Usman as he moved from garrison to garrison with his family throughout his youth demonstrate how individuals move for different amounts of time and across varying distances, accumulating different resources on the way (resources which are central to his building a life in England today).

\section{Analysis}

When Usman started work he continued to access the Internet via his mobile phone in the taxi office where he worked. His primary literacy practices cut across the two domains of home and work. The analysis of the ethnographic strips revealed that Usman was spending increasing amounts of time communicating via the photo-posting feature of Facebook. This was because Nadia had bought Usman a smartphone soon after his arrival in the UK. Usman's literacy practices changed as the affordances of the smartphone allowed him to access the Internet outside the home and take photographs which he introduced more easily into his communications. The strips revealed that Usman went online largely in the afternoons, before going to work, though he often logged into his Facebook profile to chat during late shifts at work. The extracts presented here were selected due to the extent of the language varieties used: Part 1 contains the greatest amount of language mixing while Part 2 contains the greatest amount of English. Part 3 relates to an interaction using Instant Messaging which occurred, unprompted, while I was present with Usman.

Translation for extracts:

Bold italic $=$ Mirpuri Punjabi

Italic $=\mathrm{Urdu}$

Bold $=$ English

\section{Part 1 Posting: Trafford}

1. Salman: teri o phet gaya ha tou to $: P$ 
(you look 'spoiled':P)

\section{Usman: Pai ji kha pi kay say jao to yehi hoga na lol}

(this is what happens when you eat too much and go to sleep lol)

3. Salman: (aho a v gal sahi ha ahir d...ka yahi kam to hota khata peta $\mathrm{n}$ sata

(that's true, after all, that's all there is to do, eat, drink and sleep)

4. Salman: tou abi tk jag raha ha? Ghar ki chokidari :P

(Why are you still up? Are you nightguarding :P)

5. Usman: Kutay job pe hun haraami

(Dog I'm at the job bastard)

6. Salman: chokidari ki job gud job pc ktna pound kma raha ha?

(It's a gud job of nightwatchman you know how many pounds are you earning from that?)

The extract begins with an exchange between Salman and Usman in Mirpuri. Mirpuri is not often found written in public domains because it is an informal spoken variety which does not carry the same prestige, outside domestic contexts, as Urdu or English. They have gained access to this through their vernacular practices, firstly, Usman told me, through their use of spoken Mirpuri, and then through their creative experiments with Mirpuri using romanized script in email and text messaging on their mobile phones. This leakage between domain boundaries began in Mirpur but was extended when Usman started using a smartphone in the UK.

\section{What practices are being remitted in the Trafford postings?}

\section{Literacy in Mirpuri}

The prestige of Mirpuri in domestic settings came across when Usman described the word 'phet', in line 1, as 'pure Pahari' which they used together because 'Salman is the close one'. Usman's privacy settings allow all his Facebook friends to see these comments, thus the interaction is semi-public. The Punjabi-Pahari-Potwari language continuum has no standard written form in Pakistan but is by far the widest spoken complex of language varieties, unlike Urdu which has a formal standardized written form. It is characterized in online writing by abbreviations and differences in spelling. Usman told me that he and his friends create their own spellings for Mirpuri. In this instance, I see this as an individual remittance as Usman and Salman share these specific abbreviations with each other alone having begun to use them in mobile phone text messages to each other in Pakistan. They extend the possibilities 
of this script each time they remit the script back and forth between each other. I use the term remit to emphasise the social value this script has for maintaining their friendship. The narrow sense of 'share' refers to 'joint use' whereas the wider definition goes further in expressing that something has been given. 'Remit' goes even further. It recognises that, like the economic remittances that Usman sends back to Pakistan, Usman and Salman's literacy in Mirpuri has value in extending their friendship each time they create new spellings together in a variety which connotes domestic prestige.

\section{Literacy in non-standard Urdu}

This creative linguistic work can also be seen in the use of Urdu. An example of this is the negotiation of the 'chokidar' identity which Salman playfully imposes on Usman. In lines 4-6 Salman jokes about whether Usman is in fact a night guard as he can see that Usman is awake late at night, even though Salman knew that he was working night shifts. The term chokidar is a term used in South Asia for watchmen who guard buildings to keep out intruders. The humour for a Pakistani audience is that chokidars have low status in Pakistan and so this would not be considered appropriate employment for Usman's caste. Up to line 5, Salman uses only Mirpuri and Urdu, yet in line 6 he uses three English words from his repertoire: 'good', 'job' and 'pounds'.

Being a 'chokidar' could only be seen as a good job if it is translated to 'night guard' and if it was well paid in Britain. Chokidars earn very low wages in Pakistan, whereas guards can earn relatively good salaries for Mirpuris in Britain. Historically, the chain migration that resulted in Usman's move to Lancashire means that it is well known in Mirpur that the benefits of a UK salary, even for low-status work, sustains Mirpuri migration to Britain through economic remittances. However, this chain migration is fraught with risks, from the emasculation of what Charsley calls the 'imported husband' (2005) to the increasing threat of Islamophobia in Britain. Beliefs about these risks are remitted in Salman's choice of the Urdu word chokidar as it can be seen as a negative comment on Usman's migration and, perhaps, on the wider transnational practice of Mirpuri migration to Britain. Levitt notes that not all remittances are positive (2016).

\section{How do beliefs about language challenge and transform migrants' practices?}

When I asked Usman why Salman switched to Urdu, he replied: 


\section{Part 2: Poor Noor}

In this section I analyse a different set of postings which relate to a photograph Usman posted of him holding his baby son Oman and standing next to his step-son Noor whose arm is bandaged. Zara is Usman's wife's cousin. The postings were made during the same meaningmaking trajectory as the interviews were carried out. Analysing the strips in this trajectory, particularly those full of reference to my fieldnotes, highlighted that Usman was homesick during this time. He told me he had not made any new friends in Lancashire.

\section{Zara: What's happened to poor Noor!!!!!}

2. Usman: He slipped while walking and broke his arm

3. Zara: Aw bless him.hpe he gets better 


\section{Usman: He is better now been through operation he is good now}

The indirect speech act 'Wats happened to poor Noor!!!!!' demands an explanation for Noor's bandaged arm, followed by subsequent explanations from Usman. This extract takes place in English. It is presented here as it demonstrates the role of literacy in English among Pakistani families at a time when proficiency in English is conflated with allegiance to Britain.

In line 2, Usman addresses Zara's question in standard British English. In his next posting, he moves to Pakistani English, remitting both varieties across this transnational network of readers. I use the term 'remit' here as Usman deploys his literacies strategically. He is not simply sharing them, but rather, he is demonstrating his proficiency in both varieties as each extends his social capital given the prestige of English in his transnational network. In line 4, his arguments are effectively grouped together. He omits the auxiliary verb 'has' and the indefinite article 'an' when he explains that Noor has 'been through operation' though he still displays considerable grammatical competence when writing in formal English. In Pakistani English, the use of the phrasal verb 'been through' collocates with 'operation' rather than 'have an operation' in British English. He manipulates the sequence of events by changing their order to foreground the fact that Noor is better. This, I argue, is central to Usman's goal of convincing Zara, and the rest of his wife's relatives who are reading, that he is a responsible stepfather. The choice of verb forms is an important part of a narrative in which Usman constructs this identity. He is able to do this because the grammar which was made available to him through the sponsorship of literacy in English in schools in Pakistan is now taken up online in the UK. Usman extends his social capital when he remits these literacy practices because the prestige of these varieties of English to different readers of his posts enable him to maintain transnational ties while also integrating into the local network in Lancashire.

\section{How do beliefs about language challenge and transform migrants' practices?}

In the interview about language choice, Usman attributes Zara's use of English to her being from 'here', meaning Lancashire and/or Britain. English is an iconic representation of Britishness and is taken as an inherent characteristic of Zara's social group. However, Usman told me that he uses spoken English words occasionally with his Mirpuri family in Lancashire but communicates with all of his relatives using spoken Mirpuri, code-switching to English. 
This was confirmed during my visits to Usman's family's houses in MMT-1 to MMT-4. This extract and the associated postings imply the opposite online, that English is used between family members on Facebook when the majority of them use Mirpuri face-to-face. Initially I felt that this use of English in the semi-public space of Facebook may have reflected the prestige of English in online domains, or was perhaps the result of repeated calls for Pakistani Muslims to use English in public. However, when I asked Usman why Zara doesn't use Mirpuri or Urdu online, he explained during an interview in meaning-making trajectory 4 :

Usman: [interrupting] because she doesn't know how to do the roman ... I think so ... maybe she does but she don't do it with me ... 'cause 'er doing the roman thing is quite frank quite frank. If I use roman with you then that means I'm alright with you. And she's ... em ... she's wife of my cousin so she's so if she wants to talk to me she'll make out like it's alright

Tony: So is it to do with how formal the language is?

Usman: Yup it does 'cause if the person like like like ... if you knew the roman English I'll use the roman English with you but you don't know so that's why I use English ... er I won't use the roman English with my uncle

Usman's response 'I don't think she knows how to speak Punjabi Urdu' suggests that, out of politeness, he did not want to suggest that a relative of his could not do something that he could. However, he continues by describing the appropriateness of different forms of language online, explaining that Mirpuri is 'too frank,' that it would be inappropriate for the wife of his cousin to use Mirpuri with him. In gendering the construction of writing online, Usman suggests that Zara may indeed know how to use roman script but that it would be inappropriate for her to do so because of gender-role definitions. Further to this, the term 'uncle' in the following turn implies that it would also be inappropriate for an older male relative. In this extract it seems that, as with Levitt's work, standards of age and gender appropriateness are remitted, though in this example they are remitted in the gendered ideologies which shape Facebook posts.

\section{Part 3}

In Part 3, the online communication is from Facebook's Instant Messaging and occurred during meaning-making trajectory 4. Usman and I were seated in front of the computer reading his postings when 'what's going on?' appeared on Instant Message, written by his younger brother Zahir. 


\section{Extract 1:}

Tony: why is your brother writing to you in English?

Usman: Every time this one every time yeah

Tony: Really. Why would he do that?

Usman: I don't know 'cause I told him to do that, it's good

Tony: Really

Usman: Look at that [pointing to Zahir's on-screen written English and quoting Zahir's words] 'what's going on?' he's alright with English, he's very much alright with English

Tony: Yeah I know they're alright with English but...

Usman [interrupting]: why do they choose it? 'cause 'cause this one [Zahir] he don't use mobile as much he has the thing with the mobiles. I use mobiles so much so I know I can [pointing to abbreviated word] what does that mean and all that. He don't use mobiles as much

Tony: Ah right so you can understand some of the...

Usman ...some of the slang and all that cos I used to do it but he never do it

Tony: $A h O K$

Usman: You know he just studies and so he knows English

Usman begins with hyperbole: 'every time this one' and suggests that he was the reason for Zahir's use of written English. This role of literacy mediator was a common feature of Usman's family responsibilities prior to his migration and he continues with this role online from Lancashire. The intensification strategy, 'he's alright with English' helps Usman to construct his brother Zahir as a good user of English, which seems to be important to him.

In 'He don't use mobiles as much' Usman constructs a relationship between using mobile phones and developing the ability to use the implied language forms of slang Urdu. He links his own creativity with digital literacy and his use of mobile phones. This is confirmed with 'he never does it' and the intensifying 'just/so' in 'he just studies so he knows English'. English connotes formal standard English. There appears to be an implicit opposition 
between learning standard English in one's studies and learning non-standard English on a mobile phone. For Usman, it would seem the boundaries between language varieties are broken down when he takes up the affordances of new technologies (mobile phones). The argument runs: if Zahir would use his mobile phone more for writing texts messages he would also be able to use 'slang' English, the implied language form, like Usman. The value of these remittances may lie, therefore, in the individual user's ability to extend their language practices as part of their creativity with technology. For Usman his social remittances are perhaps higher in value because his literacy practices enable him to move across the boundaries of language varieties. What for him is an affordance of mobile phones is a constraint for Zahir. These varieties are immediately contrasted in the final extract where later in the same interview Usman acts as a literacy mediator for his brother's use of nonstandard English.

\section{Extract 2}

In response to Zahir asking 'what's going on?' Usman replies 'nofing'.

Tony: You're telling him to use English but then you're using informal English. Why are you doing that?

Usman: so that so that he could know that this is the word nofing so he can use it

Tony: is that a word?

Usman: Nofing [pronounced with /f/]

Tony: [spelling out the letters] N-O-F-I-N-G?

Usman: Yeah, it's not a word. Nothing is a word. But if you pronounce it nofing [Lancashire accent] so you know it's alright

Tony: So he'll know that you're teaching him informal English?

Usman: So it's alright for him to know

Tony: But Zahir isn't going to come [to Lancashire] he's not the brother who is gonna come?

Usman: He's not gonna come, no, not gonna come.

In this extract later in the same interview, Usman draws on non-standard pronunciation to explain the reason he writes 'nofing'. His use of the labiodental fricative /f/ and not the 
interdental fricative $/ \theta$ / draw on the accent which Usman has started to use since his arrival in Lancashire. My interpretation of 'but it's alright for him to know' is a justification strategy which implies that the non-standard use of 'nofing' is Usman continuing to see himself as a literacy mediator. My next question assumes that there is a link between remitting Lancashire English and Zahir coming to live in Lancashire, though Usman confirms that Zahir will not migrate. I use 'remit' here as this literacy resource circulates across the unbounded transnational network for non-migrants to use as social capital even though they will not migrate to Lancashire. The societies of origin and settlement are connected through new registers for English which have nothing to do with new migrants migrating but do still extend the transnational ties that connect Mirpuris across the world.

\section{Conclusion}

Scholars and practitioners either focus on what happens to immigrants once they arrive in a new place or what happens to immigrants in the places where they come from. Migration research needs to span migrants' origin and destination countries and go beyond economic considerations to include the social and cultural.

(Levitt, 2010: 9)

The aim of this paper was to see how the creation and circulation of transnational literacies can be seen as social remittances, part of the practices, ideas, norms and social capital that span migrants' destination and origin countries. The analysis illustrates that an important aspect of these literacies is that they are shaped by decades of hegemonic language policy which individuals subvert when appropriating scripts for Mirpuri Punjabi, Urdu and English. Usman's description of his literacies suggests that they are a continuation of the premigration literacies which he developed offline at school in Pakistan, but which have scaled out to other domains of practice when he uses 'slang Urdu' online in the UK. However, there are discontinuities as these literacies serve different purposes and are associated with 
different values and identities post-migration. For example, the cultural diffusion which takes place when Usman remits the Lancashire-inflected 'nofing', knowing that this brother will never migrate, demonstrates how local practices become incorporated into global dynamics. In doing this, Usman chooses to circulate practices which he feels are important for his brother to know regardless of the territorial boundaries in which they find themselves. These findings demonstrate that though everyday literacies may be self-sponsored, as in the case of the Facebook postings, they have their origins elsewhere (Brandt and Clinton 2002) and are always given their shape by beliefs about language. In this paper, I demonstrated how these language ideologies are related to the political processes of nation-building in Pakistan (Rassool 2007; Ayres 2009), where languages such as Urdu and English are given official roles when the local language Mirpuri Punjabi is not and illustrated a range of functions of these language choices in interaction. For example, creative experiments scripts for Mirpuri and Urdu help maintain ties with family and friends and demonstrates how scripts are remitted back and forth across transnational networks when interactants carefully select terms such as 'phet' and 'chokidar' whether or not these are positive or negative comments on migration. This creativity also revealed the permeability of these literacy resources, the domains in which they circulate and the territorial boundaries they transcend.

This analysis indicates that Mirpuri migrants draw from their everyday language and literacy resources and combine them in ways which are constantly changing but which are given shape by their wider social practices. These practices provide ample opportunities for Usman to construct new, shifting identities, while maintaining norms of age and gender appropriateness which are equally as important in building bridges with new family members. Recognising the role of literacy mediators, or what Levitt might see as bridge builders, in this cultural diffusion further establishes the usefulness of conceptualising transnational literacies as social remittances as these mediators exchange far more than 
economic resources. When they do this, transnational literacy remittances help sustain the 'networks of mutual reciprocity,' which Ballard (2008: 45) suggests are at the core of Mirpuri migration.

Integrating concepts from sociolinguistics, literacy studies and migration studies illustrates well that transnational literacies in different language varieties offer different meaningmaking resources for migrants. This supports the view that languages differ in terms of what different users can easily do with them (Barton and Lee 2013). In a world on the move, migrants translate and diffuse ideas when they deploy their language and literacy resources in a range of sites. The challenge was how to account for this multi-sitedness and multilayerdness in the transnational trajectories of the participants in this study. Drawing on Kell's recent work the methodological approach taken sought to establish these meaning-making trajectories as small threads in relation to wider sets of trajectories which then enabled the organisation of data at different scales (2015). Within these trajectories I was able to trace where remittances gained their value at different moments before and after Usman's migration. This approach shed light on the language ideologies which gave remittances their value without suggesting these ideologies were unchanging. Usman's beliefs about language were shaped by his language use in Pakistan but also by his language use in the taxi office in the UK. The methodological approach taken allowed me to account for these shifting ideologies as social remittances are clearly about movement and value at different stages of migration. The framework developed here helped to pin down Usman's meaning-making soon after arrival without neglecting his literacy practices prior to departure. I could not possibly have accompanied Usman at every moment during his first few months in country, and though only partial, this approach was an attempt to map the relations which were part of Usman's meaning-making during this important time for him. The findings suggest that transnational literacies enable Usman's network of family and friends to maintain kinship ties 
when they remit practices, norms and identities by building social capital each time these literacies are remitted.

\title{
References
}

\author{
Ayres, A. 2009. Speaking like a state: Language and nationalism in Pakistan. Cambridge \\ University Press.
}
Ballard, R. 2008. The political economy of migration: Pakistan, Britain and the Middle East. In V. S. Kalra (ed.), Pakistani diasporas: Culture, conflict, and change. Oxford University Press.
Ballard, R. 1991. 'Azad Kashmir: the view from Mirpur'. Economic and Political Weekly, Bombay.
Ballard, R. 2003. A case of capital-rich under-development: The paradoxical consequences of successful transnational entrepreneurship from Mirpur. In Contributions to Indian sociology 37/12: 49-81.

Barton, D and M. Hamilton. 1998. Local Literacies. Routledge. 
Barton, D., Hamilton, M. and Ivanič, R. 2000. Situated literacies: Reading and writing in context. Routledge (eds.).

Barton, D. and C. Lee. 2013. Language Online: Investigating Digital Texts and Practices. Routledge.

Baynham, M. and M. Prinsloo. 2009. The future of literacy studies. Palgrave Macmillan (eds.).

Blackledge, A. 2005. Discourse and Power in a Multilingual World. John Benjamins.

Blommaert, J. 2008. Grassroots Literacy. Routledge.

Brandt. D. 1998. Sponsors of literacy. College Composition and Communication, 49/2: $165-185$.

Brandt, D. and Clinton, K. 2002. Limits of the local: Expanding perspectives on literacy as social practice. Journal of Literacy Research 34/3: 337-356.

Charsley, K. 2005. Unhappy husbands: Masculinity and migration in transnational Pakistani marriages. Journal of the Royal Anthropological Institute 11/1: 85-105. 
Author, 2016a, Multilingual Literacies, Identities and Ideologies: Exploring Chain Migration from Pakistan to the UK. Palgrave Macmillan.

\begin{abstract}
Author, . 2016b, 'Literacy Mediation in Marriage Migration from Pakistan to the UK:
Challenging Bureaucratic Discourses to Get a Visa', Discourse and Society 27/5: 481-499.
\end{abstract}

Author, . 2018. Home Literacies: The Access and Availability of Written Material in the Homes of Mirpuri Migrants in Pakistan and the UK in Bahun, S., \& Petrić, B. (eds.) Thinking home: Interdisciplinary dialogues. Bloomsbury.

Hanks, W. 2005. Explorations in the deictic field. Current Anthropology, 46/2, 191-219.

Irvine, J. T., and S. Gal. 2000. Language ideology and linguistic differentiation. In P. V. Kroskrity (ed.), Regimes of language: Ideologies, polities and identities. School of American Research Press.

\author{
Ivanič, R., Edwards, R., Barton, D., Martin-Jones, M., Fowler, Z., Hughes, B., Mannion, \\ G., Miller, K., Satchwell, C. and Smith, J. 2009. Improving learning in college: \\ Rethinking literacies across the curriculum. Routledge.
}

Kell, C. 2008 Weighing the scales: Recontextualisation as horizontal scaling. In M. Baynham, J. Collins and S. Slembrouck. (eds) Globalisation and language contact: Scale, Migration and Communicative Practices. Continuum. 
Kell, C. 2015. Making people happen: materiality and movement in meaning-making trajectories. Social Semiotics 25/4: 423-445.

Lacroix, T., Levitt, P., and Vari-Lavoisier, I. 2016. Social remittances and the changing transnational political landscape. Comparative Migration Studies 4:16

Levitt, P. 1998. 'Social Remittances: A Local-Level, Migration-Driven Form of Cultural Diffusion', International Migration Review 32/124: 926-949

Levitt, P. and Lamba-Nieves, D. 2010. "It's Not Just About the Economy, Stupid" - Social Remittances Revisited. Migration Policy Institute. Accessed on November 12, 2017 from http://www.migrationinformation.org/Feature/display.cfm?ID=783

Levitt, P. 2016 Social Remittances: How migrating people drive migrating culture. In Triandafyllidou, A. (ed), Routledge Handbook of Immigration and Refugee Studies. Routledge.

Lothers, L. \& Lothers, M. D. 2007. Pahari and Pothwari: a sociolinguistic survey. Frontier Language Institute.

Martin-Jones, M., and Jones, K. 2000. Multilingual literacies. In M. Martin-Jones, \& K. Jones (eds), Multilingual literacies. John Benjamins. 
Rassool, N. 2007. Global Issues in Language, Education and Development: Perspectives from Postcolonial Countries. Multilingual Matters.

Street, B. 1984. Literacy in theory and practice. Cambridge University Press.

Vertovec, S. 2009. Transnationalism. Routledge.

Warriner, D. S. 2007. Transnational literacies: Immigration, language learning, and identity. Linguistics and Education 18 3/4: 201-14.

Woolard, K. 1998. Introduction: Language Ideology as a field of inquiry. In B. Schieffelin, K. Woolard \& P. Kroskrity (eds), Language ideologies: Practice and theory. Oxford University Press. 